\title{
Article
}

\section{Toward Enhanced Humidity Stability of Triboelectric Mechanical Sensors via Atomic Layer Deposition}

\author{
Wook Kim ${ }^{1,+}$, Sumaira Yasmeen ${ }^{2,+}$, Chi Thang Nguyen ${ }^{2}$, Han-Bo-Ram Lee ${ }^{2, *}$ and Dukhyun Choi ${ }^{1, *}$ \\ 1 Department of Mechanical Engineering (Integrated Engineering Program), Kyung Hee University, \\ Yongin 17104, Korea; choice124@khu.ac.kr \\ 2 Department of Materials Science and Engineering, Incheon National University, Incheon 22012, Korea; \\ sumairayasmeen51@gmail.com (S.Y.); victornguyen@inu.ac.kr (C.T.N.) \\ * Correspondence: hbrlee@inu.ac.kr (H.-B.-R.L.); dchoi@khu.ac.kr (D.C.) \\ + These authors equally contributed to this work.
}

check for updates

Citation: Kim, W.; Yasmeen, S.;

Nguyen, C.T.; Lee, H.-B.-R.; Choi, D. Toward Enhanced Humidity Stability of Triboelectric Mechanical Sensors via Atomic Layer Deposition. Nanomaterials 2021, 11, 1795. https:// doi.org/10.3390/nano11071795

Academic Editor: Jyh-Ming Wu

Received: 31 May 2021

Accepted: 8 July 2021

Published: 9 July 2021

Publisher's Note: MDPI stays neutral with regard to jurisdictional claims in published maps and institutional affiliations.

Copyright: (C) 2021 by the authors. Licensee MDPI, Basel, Switzerland. This article is an open access article distributed under the terms and conditions of the Creative Commons Attribution (CC BY) license (https:// creativecommons.org/licenses/by/ $4.0 /)$.

\begin{abstract}
Humid conditions can disrupt the triboelectric signal generation and reduce the accuracy of triboelectric mechanical sensors. This study demonstrates a novel design approach using atomic layer deposition (ALD) to enhance the humidity resistance of triboelectric mechanical sensors. Titanium oxide $\left(\mathrm{TiO}_{\mathrm{x}}\right)$ was deposited on polytetrafluoroethylene (PTFE) film as a moisture passivation layer. To determine the effective ALD process cycle, the $\mathrm{TiO}_{\mathrm{x}}$ layer was deposited with 100 to 2000 process cycles. The triboelectric behavior and surface chemical bonding states were analyzed before and after moisture exposure. The ALD-TiO -deposited PTFE showed three times greater humidity stability than pristine PTFE film. Based on the characterization of $\mathrm{TiO}_{\mathrm{x}}$ on PTFE film, the passivation mechanism was proposed, and it was related to the role of the oxygen-deficient sites in the $\mathrm{TiO}_{\mathrm{x}}$ layer. This study could provide a novel way to design stable triboelectric mechanical sensors in highly humid environments.
\end{abstract}

Keywords: atomic layer deposition; surface control; humidity stability; triboelectric behavior

\section{Introduction}

The expansion of personal and mobile electronic devices, and rapid developments in information and communication technology (ICT), are noticeably changing our modern civilization. These phenomenal developments have introduced a new age, called the fourth industrial revolution. In the fourth industrial revolution, there are several key technologies such as Internet of Things (IoTs), artificial intelligence (AI), big data analysis, three-dimensional (3D) printing, and augmented reality. In addition to the development of these key technologies, their integration has been processed toward smart platforms, such as a smart factory, smart healthcare, and smart city. To establish the smart platforms, it is important to obtain correct data from environments by using sensors. Therefore, the importance and necessity of efficient and precise sensors has increased.

To satisfy societal demands, various sensors based on the piezoresistive effect [1-3], capacitive sensing [4-6], and piezoelectric behavior [7-9] have been investigated. Triboelectric effect-based sensors have been investigated to develop reliable mechanical and chemical sensors. The triboelectric sensors can detect changes in pressure [10-14], mechanical motion [15-19], position [20], vibration [21-23], velocity [24-26], liquid volume [27,28], and various chemicals in different phases [29-32]. Generally, the operation of triboelectric sensors is based on contact electrification and electrostatic induction [33-35]; specifically, the triboelectric behavior is based on surface phenomena. Therefore, triboelectric behavior and the corresponding signals are affected by an external environment. When the sensors are exposed to an environment, triboelectric sensors can be contaminated by organic/inorganic contaminants and $\mathrm{H}_{2} \mathrm{O}$ from air. Especially, the $\mathrm{H}_{2} \mathrm{O}$ in air can be a serious issue for the functionality of triboelectric mechanical sensors. $\mathrm{H}_{2} \mathrm{O}$ in air can form 
a conductive layer on tribo-materials, and the accumulated surface charges can dissipate through the $\mathrm{H}_{2} \mathrm{O}$ layer [36], which means that triboelectric sensors in a high relative humidity can provide incorrect data. Therefore, various researchers have focused on the development of humidity-resistant triboelectric devices based on physical sealing [37,38], material engineering [39-41], and surface engineering [42].

Atomic layer deposition (ALD) is a thin film deposition technique developed for the nanofabrication of integrated circuit systems, and it has been intensively studied and applied to various applications [43-45]. ALD enables the precise control of film thickness to the Angstrom scale with excellent conformality based on its unique self-saturation surface reactions. ALD is utilized for the design of electronic devices such as metal-insulatormetal (MIM) capacitors [46,47] and metal-oxide-semiconductor field effect transistors (MOSFETs) [48,49]. Additionally, ALD can be utilized to form an anti-corrosion layer for stable solar-based water splitting $[50,51]$. The functionality of photoanodes is maintained and the ALD-processed layer can act as a passivation layer because of the extremely low thickness and high uniformity.

In this work, we demonstrated a novel moisture passivation technique to maintain the functionality of triboelectric mechanical sensors. Especially, we aimed to propose the humidity passivation technique for triboelectric mechanical sensors that utilize the human skin as a counter tribo-material. Therefore, we selected a negative tribo-material, which is capable of the ALD process. ALD- $\mathrm{TiO}_{x}$ was deposited on a negative tribo-material, polytetrafluoroethylene (PTFE). To determine the effective process cycles for enhanced moisture passivation capability, triboelectric behaviors of $\mathrm{TiO}_{\mathrm{x}}$-deposited PTFE films were evaluated and their physical characteristics were analyzed. The moisture passivation was related to the characteristics of the $\mathrm{TiO}_{\mathrm{x}}$ layer on PTFE films. In addition, the moisture resistance could be improved by approximately three times compared with the pristine PTFE film. We expect that our technique can provide a novel method for developing stable and reliable triboelectric mechanical sensors in highly humid conditions.

\section{Materials and Methods}

\subsection{Deposition of $\mathrm{TiO}_{x}$ on PTFE Film}

$\mathrm{TiO}_{x}$ was deposited on a tribo-material using ALD. Before depositing $\mathrm{TiO}_{x}$, the PTFE film was attached to an $\mathrm{Al}$ sheet with an area of $1.5 \mathrm{~cm} \times 1.5 \mathrm{~cm}$. The ALD process was then conducted after loading the prepared PTFE/Al sheet. $\mathrm{TiO}_{\mathrm{x}}$ was deposited in a traveling wave-type reactor at a temperature of $150{ }^{\circ} \mathrm{C}$. Nitrogen $\left(\mathrm{N}_{2}\right)$ was utilized as the carrier and purging gas. The base pressure was $1.12 \times 10^{-1}$ Torr and the purge gas flow was $100 \mathrm{sccm}$. The titanium (IV) isopropoxide (TTIP) precursor was pulsed for $5 \mathrm{~s}$ and the water $\left(\mathrm{H}_{2} \mathrm{O}\right)$ reactant was pulsed for $1 \mathrm{~s}$. An amount of 100, 300, 500, and 2000 deposition cycles were conducted to define the optimal ALD cycle to improve moisture resistance.

\subsection{Assembly of the TENG Device and Triboelectric Performance Measurement}

The prepared $\mathrm{TiO}_{x}$-deposited PTFE film was utilized as a negative tribo-material. An $\mathrm{Al}$ sheet was selected as a positive tribo-material. A pushing tester (JIOCS-120, Junil Tech Co., Deagu, Korea) was utilized to induce a compressive load on the TENG device. The measurement conditions for all samples were: a gap distance of $4 \mathrm{~mm}$, a compressive load of $5 \mathrm{~N}$, a contact frequency of $3 \mathrm{~Hz}$, and a contact area of $1.5 \mathrm{~cm} \times 1.5 \mathrm{~cm}$. Electrical outputs were measured using an oscilloscope (MDO3052, Tektronix, Beaverton, OR, USA), a low-noise current preamplifier (SR570, Stanford Research Systems, Sunnyvale, CA, USA), and an electrometer (6514 system electrometer, Keithley, Solon, OH, USA). For evaluation of the humidity resistance, samples were stored in a humid chamber with a relative humidity $(\mathrm{RH})$ of $99 \%$ for $24 \mathrm{~h}$ and the triboelectric performance was evaluated. To compare the signal loss rate, the initial triboelectric performance was measured at $\mathrm{RH} 10 \%$ and $25^{\circ} \mathrm{C}$. 


\subsection{Characterization}

A field emission scanning electron microscope (FE-SEM, SU-70, Hitachi, Tokyo, Japan) was utilized to confirm the formation of $\mathrm{TiO}_{\mathrm{x}}$ on PTFE with different process cycles. The water contact angle (WCA) of pristine PTFE and $\mathrm{TiO}_{x}$-deposited PTFE $\left(\mathrm{TiO}_{x} /\right.$ PTFE) films was measured using a droplet analyzer (SmartDrop, FemtoBioMed, Seongnam, Korea). Changes in the electronic structures were investigated using X-ray absorption spectroscopy (XAS). XAS experiments were performed at the $2 \mathrm{~A}$ beamline in the Pohang Accelerator Laboratory (PAL), Pohang, Korea. Surface chemical bonds were investigated, utilizing an X-ray photoelectron spectrometer (XPS, K-Alpha, Thermo Fisher Scientific Co., Waltham, MA, USA) with a pass energy of $20 \mathrm{eV}$ and using a monochromatic $\mathrm{Al} \mathrm{K} \alpha$ source. Survey scans were conducted to investigate the overall change of surface chemical bonds. After the survey scan, a narrow scan was performed. The $\mathrm{C} 1$ s and Ti $2 p$ peaks were observed in PTFE and $\mathrm{TiO}_{\mathrm{x}} / \mathrm{PTFE}$ samples. The narrow scan results were normalized and deconvoluted to compare the chemical bonds after depositing $\mathrm{TiO}_{\mathrm{x}}$ and exposing it to humid air for $24 \mathrm{~h}$. Finally, deconvolution of the narrow scan result was conducted to define the present chemical bonds and their portion.

\section{Results and Discussion}

\subsection{Characteristics of ALD-TiO ${ }_{x}$ on PTFE Film}

Figure 1 shows the concept of moisture passivation using $\mathrm{TiO}_{\mathrm{x}}$ formed by ALD and the moisture passivation capability of the $\mathrm{ALD} \mathrm{TiO}_{x} / \mathrm{PTFE}$ film. As shown in Figure 1a, the $\mathrm{TiO}_{x}$ layer was deposited on a PTFE surface. ALD-TiO $/$ PTFE film acts as a negative tribo-material and the aluminum $(\mathrm{Al})$ sheet acts as both an electrode and positive tribomaterial. The moisture passivation mechanism is based on the $\mathrm{H}_{2} \mathrm{O}$ absorption by oxygendeficient sites. The FE-SEM images confirm that the $\mathrm{TiO}_{x}$ layer was formed on the PTFE surface in 300-ALD process cycles, as shown in Figure $1 \mathrm{~b}$. After depositing a $\mathrm{TiO}_{\mathbf{x}}$ layer on PTFE, the moisture passivation capability with a pristine PTFE film was evaluated, as shown in Figure 1c. At the environmental humidity of RH 99\%, pristine PTFE lost $32.7 \%$ of its triboelectric voltage signal. However, $\mathrm{ALD}-\mathrm{TiO}_{\mathrm{x}} / \mathrm{PTFE}$ film showed better moisture stability, which was approximately three times greater than pristine PTFE film. The corresponding voltage signal was reduced approximately $12.6 \%$ compared with the dry condition. To understand the better humidity stability of the $\mathrm{ALD}-\mathrm{TiO}_{\mathrm{x}} / \mathrm{PTFE}$ film, the formation and physical characteristics of the ALD-TiO ${ }_{x}$ layer were first analyzed.

(a)

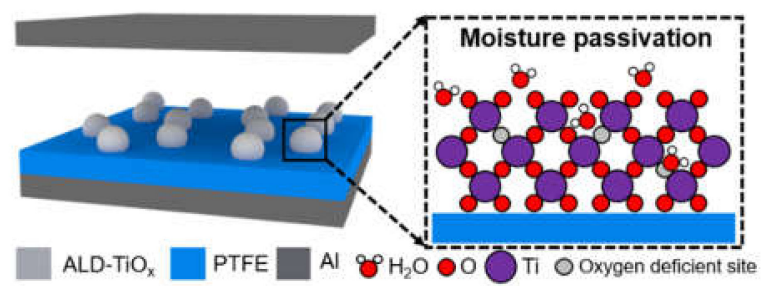

(b)

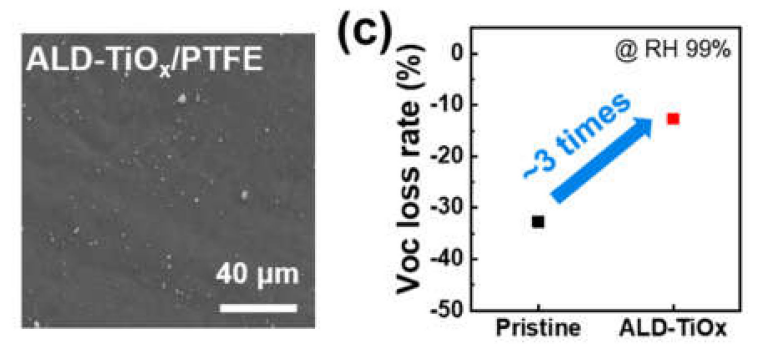

Figure 1. Concept and effectiveness of humidity passivation using $\mathrm{ALD}-\mathrm{TiO}_{\mathrm{x}}$. (a) Schematic illustration of humidity passivation using ALD-TiO . (b) FE-SEM image of the ALD-processed TiO $/$ PTFE film. (c) Open circuit voltage $\left(\mathrm{V}_{\mathrm{OC}}\right)$ loss rate of pristine PTFE and ALD-TiO $\mathrm{X}_{\mathrm{x}}$-deposited PTFE film at relative humidity $(\mathrm{RH})$ of $99 \%$. 
The surface of the ALD-TiO $/$ PTFE film was examined by the water contact angle (WCA) measurement. The average WCA value and standard deviation are presented in Figure 2a. The WCA of the pristine PTFE surface was ca. $131.6^{\circ}$ and there was no significant change in WCA after depositing $\mathrm{TiO}_{\mathrm{x}}$ with 100 ALD cycles $\left(100-\mathrm{TiO}_{\mathrm{x}}\right)\left(\mathrm{ca} .130 .9^{\circ}\right)$. As the number of ALD cycles increased to 300 cycles $\left(300-\mathrm{TiO}_{\mathrm{x}}\right)$, the contact angle decreased to $128.1^{\circ}$ because of the formation of the $\mathrm{TiO}_{\mathrm{x}}$ layer. The WCA rapidly decreased to $119.3^{\circ}$ and $108.2^{\circ}$ after 500 ALD cycles $\left(500-\mathrm{TiO}_{\mathrm{x}}\right)$ and 2000 ALD cycles $\left(2000-\mathrm{TiO}_{\mathrm{x}}\right)$, respectively. The change in WCA is related to the distribution of the $\mathrm{TiO}_{\mathrm{x}}$ layer. Figure $\mathrm{S} 1$ indicates the top-view FE-SEM images with EDS mapping of the Ti distribution. As shown in Figure S1a, there were no Ti atoms on the pristine PTFE film. It was difficult to identify $\mathrm{Ti}$ atoms from the 100- $\mathrm{TiO}_{\mathrm{x}} / \mathrm{PTFE}$ film, similar to the pristine PTFE film (Figure S1b). However, from 300- to 500- $\mathrm{TiO}_{\mathrm{x}} / \mathrm{PTFE}$ films, irregular island-shaped $\mathrm{TiO}_{\mathrm{x}}$ particles were observed (Figure S1c,d). This island-growth is related to the $\mathrm{TiO}_{\mathrm{x}}$ nucleation on the PTFE surface. When the ALD process is conducted on polymeric materials, the $\mathrm{C}=\mathrm{O}$ bonds act as nucleation sites for ALD growth [52]. However, an ideal PTFE film has only $\mathrm{C}_{2} \mathrm{~F}_{4}$ bonds, resulting in difficult $\mathrm{TiO}_{\mathrm{x}}$ nucleation on a PTFE surface without surface treatments such as plasma etching. In this work, we utilized an industrial PTFE film with a purity of 99.9\%. Therefore, the $\mathrm{TiO}_{\mathrm{x}}$ nucleation might progress at impurities in the PTFE film. In a 2000- $\mathrm{TiO}_{\mathrm{x}} /$ PTFE film, a $\mathrm{TiO}_{\mathrm{x}}$ film was formed on the PTFE (Figure S1e). As a result, the $\mathrm{TiO}_{\mathrm{x}}$ layer was grown from island to film as the ALD cycle increased. Thus, we assumed that the triboelectric performance would proportionally decrease with an increase in ALD cycles because of the transition of tribo-materials from PTFE to $\mathrm{TiO}_{\mathrm{x}}$. Figure $2 \mathrm{~b}$ indicates the normalized oxygen k-edge XAS spectra of pristine PTFE (light gray line), $\mathrm{TiO}_{\mathrm{x}}$ (gray line), and $300-\mathrm{TiO}_{\mathrm{x}} /$ PTFE composite surface (red line). $\mathrm{TiO}_{\mathrm{x}}$ has a peak at a photon energy of $531 \mathrm{eV}$ and PTFE has a peak at $533 \mathrm{eV}$. In the hybridized spectrum, noticeable peaks from $\mathrm{TiO}_{x}$ and PTFE were observed, which means that the $\mathrm{TiO}_{x}$ and PTFE co-exist at the surface when the ALD process is conducted with a relatively low ALD cycle. In addition, the XAS spectra show that the dominant surface material of the $300-\mathrm{TiO}_{\mathrm{x}} / \mathrm{PTFE}$ film is PTFE. Therefore, we expected that the triboelectric performance of hybridized surface might be similar to that of pristine PTFE. The chemical bonding state of the $\mathrm{TiO}_{\mathrm{x}}$ layer with $\mathrm{Ti} 2 p$ spectrum was evaluated, as shown in Figure $2 \mathrm{c}$. The $\mathrm{Ti} 2 p$ spectrum of $300-\mathrm{TiO}_{\mathrm{x}}$ was deconvoluted, and different $\mathrm{Ti}$ states of $\mathrm{Ti}^{4+}(60.16 \%)$ and $\mathrm{Ti}^{3+}(39.84 \%)$ existed in the $\mathrm{TiO}_{\mathrm{x}}$ layer. The $\mathrm{O} 1$ s spectrum of $300-\mathrm{TiO}_{\mathrm{x}}$ was deconvoluted as well, as indicated in Figure S2a. The deconvoluted $\mathrm{O} 1$ s spectrum also designates the presence of $\mathrm{Ti}^{3+}$. In the $500-\mathrm{TiO}_{\mathrm{x}}$ film, there were two different states, as shown in Figure S3(ai), 56.7\% $\mathrm{Ti}^{4+}$ and $46.3 \% \mathrm{Ti}^{3+}$. Therefore, the humidity passivation might be related to the oxygen-deficient sites in the ALD- $\mathrm{TiO}_{\mathrm{x}}$ layer.
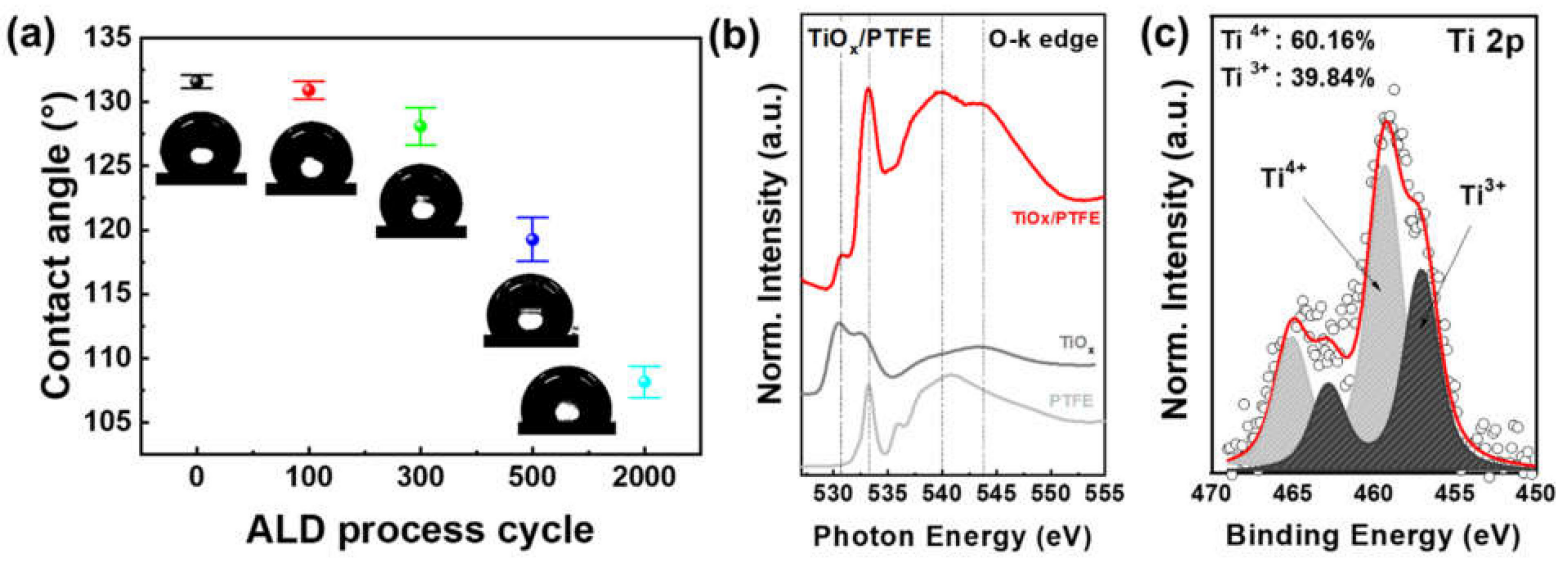

Figure 2. Effects of the $\mathrm{ALD}-\mathrm{TiO}_{\mathrm{x}}$ layer on the surface property. (a) Changes in the contact angle with an increase in number of ALD cycles. (b) Oxygen-K edge XAS spectra of pristine PTFE (light gray), TiOx (gray), and ALD-TiO $/$ PTFE films (red). (c) Deconvoluted Ti $2 p$ XPS spectrum of the ALD-TiO layer with 300 ALD cycles. 


\subsection{Triboelectric Behavior of the ALD-TiO ${ }_{x} /$ PTFE Film}

After confirming the existence and formation of $\mathrm{TiO}_{\mathrm{x}} / \mathrm{PTFE}$ composite surfaces, their triboelectric behaviors were evaluated, as shown in Figure 3. Figure 3a-c show the measured open circuit voltage $\left(\mathrm{V}_{\mathrm{OC}}\right)$, short circuit current $\left(\mathrm{I}_{\mathrm{SC}}\right)$, and charge density $(\sigma)$ at $\mathrm{RH}$ $10 \%$ and $25{ }^{\circ} \mathrm{C}$. The overall triboelectric performances decreased with the deposition of $\mathrm{TiO}_{\mathrm{x}}$ layers. Pristine PTFE produced a $\mathrm{V}_{\mathrm{OC}}$ of $30.1 \mathrm{~V}$ and an $\mathrm{ISC}_{\mathrm{SC}}$ of $0.98 \mu \mathrm{A}$, respectively, and its surface charge density was $4.61 \mathrm{nC} / \mathrm{cm}^{2}$. However, the triboelectric performances significantly decreased with the $100-\mathrm{TiO}_{\mathrm{x}} / \mathrm{PTFE}$ film. The measured $\mathrm{V}_{\mathrm{OC}}, \mathrm{I}_{\mathrm{SC}}$, and $\sigma$ values were $5.4 \mathrm{~V}, 0.24 \mu \mathrm{A}$, and $0.81 \mathrm{nC} / \mathrm{cm}^{2}$, respectively. The the 300-TiO $/$ $/$ PTFE film produced larger triboelectric signals than the 100-TiO $\mathrm{X}_{\mathrm{x}} / \mathrm{PTFE}$ film. The generated $\mathrm{V}_{\mathrm{OC}}, \mathrm{I}_{\mathrm{SC}}$, and $\sigma$ were $11.4 \mathrm{~V}, 0.33 \mu \mathrm{A}$, and $1.7 \mathrm{nC} / \mathrm{cm}^{2}$, respectively. The $500-\mathrm{TiO}_{\mathrm{x}} / \mathrm{PTFE}$ film showed the highest performance among the $\mathrm{ALD}-\mathrm{TiO}_{\mathrm{x}}$-deposited PTFE films in this work. The detected average triboelectric signals were $16.6 \mathrm{~V}, 0.55 \mu \mathrm{A}$, and $2.8 \mathrm{nC} / \mathrm{cm}^{2}$, respectively. Finally, the triboelectric performance of a $2000-\mathrm{TiO}_{\mathrm{x}} / \mathrm{PTFE}$ film was evaluated. The generated $\mathrm{V}_{\mathrm{OC}}$ and $\mathrm{ISC}_{\mathrm{SC}}$ were $5.8 \mathrm{~V}$ and $0.17 \mu \mathrm{A}$, respectively, and the accumulated charge was $1.0 \mathrm{nC} / \mathrm{cm}^{2}$, which is slightly greater than that of the $100-\mathrm{TiO}_{x} / \mathrm{PTFE}$ sample. Furthermore, the mechanical durability of $\mathrm{ALD}^{-\mathrm{TiO}_{\mathrm{x}}} / \mathrm{PTFE}$ film $\left(300-\mathrm{TiO}_{\mathrm{x}} / \mathrm{PTFE}\right)$ was assessed to ensure the stability of the ALD-TiO layer, as shown in Figure S4. The ALD-TiO $/$ PTFE film showed a constant output signal after 60,000 contact/separation trials over $5 \mathrm{~h}$. This result shows that the $\mathrm{ALD}-\mathrm{TiO}_{\mathrm{x}}$ layer will be maintained under the mechanical stimulation.

(a)
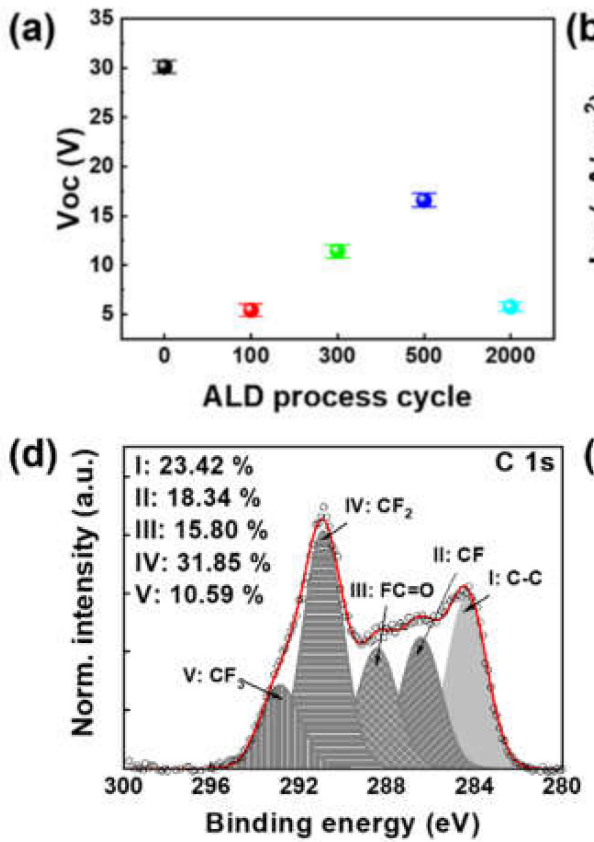
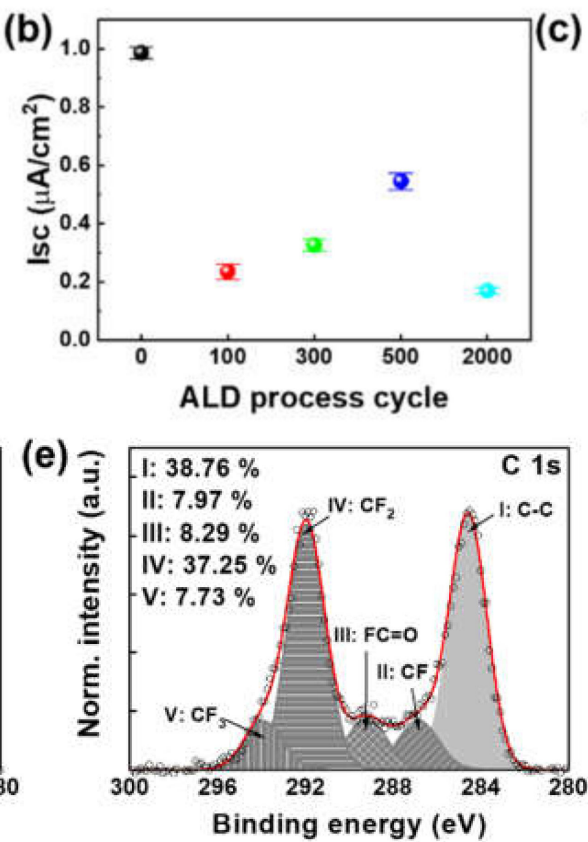

(c)

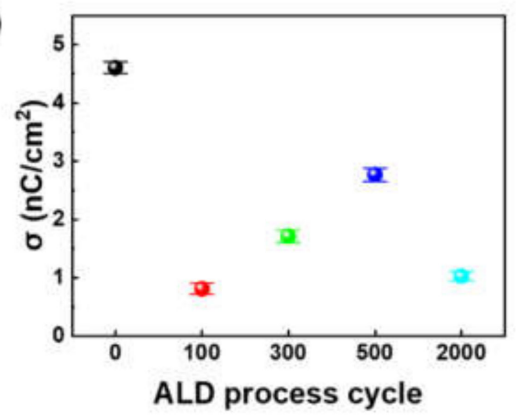

(f)

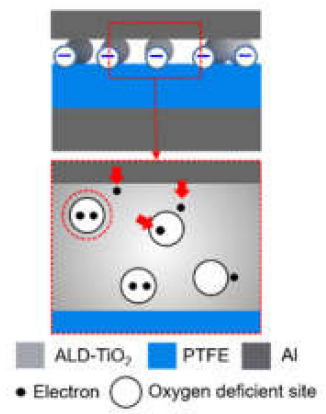

Figure 3. Effects of the $\mathrm{ALD}-\mathrm{TiO}_{\mathrm{x}}$ layer on triboelectric outputs. Changes in (a) the open circuit voltage $\left(\mathrm{V}_{\mathrm{OC}}\right),(\mathbf{b})$ short circuit current $\left(\mathrm{I}_{\mathrm{SC}}\right)$, and (c) charge density $(\sigma)$ as a function of ALD cycles. Deconvoluted C 1s XPS spectra of (d) pristine PTFE film and (e) 300-TiO $/$ PTFE film. (f) Schematic illustration of the electron trap mechanism according to the oxygen deficient sites.

After confirming the triboelectric signals of $\mathrm{ALD}-\mathrm{TiO}_{\mathrm{x}} / \mathrm{PTFE}$ films, we tried to understand the cause of electrical output attenuation. The output reduction in the 2000$\mathrm{TiO}_{x} /$ PTFE film can be explained based on the FE-SEM and EDS results in Figure S1e. After conducting the ALD process with 2000 cycles, the PTFE surface was completely covered by $\mathrm{TiO}_{x}$ thin film, which means that the triboelectric material changed to a $\mathrm{TiO}_{x}$ thin film. $\mathrm{TiO}_{\mathrm{x}}$ is a relatively positive tribo-material compared with PTFE. Therefore, the reduction in the triboelectric performance is inevitable when the $\mathrm{TiO}_{\mathrm{x}}$ film is formed on the PTFE surface. Figure 3d,e show the deconvoluted $C 1$ s spectra of a pristine PTFE and $300-\mathrm{TiO}_{x} /$ PTFE film. As shown in Figure 3d, pristine PTFE film has various chemical 
bonds, such as $\mathrm{C}-\mathrm{C}, \mathrm{CF}, \mathrm{CF}_{2}, \mathrm{CF}_{3}$, and $\mathrm{FC}=\mathrm{O}$. As expected, there was a $\mathrm{FC}=\mathrm{O}$ bond, which can act as a nucleation site during the ALD process. After 300 ALD cycles, there were changes in the chemical bonding states, as indicated in Figure 3e. Originally, the chemical bonding states, which were bonded with fluorine atoms, were $76.58 \%$ in the pristine PTFE. However, after forming the $\mathrm{TiO}_{\mathrm{x}}$ layer, the portion of detected fluorine decreased to $61.24 \%$, which is an approximately $15 \%$ decrease. In addition, the portion of $\mathrm{FC}=\mathrm{O}$ bonds decreased from $15.8 \%$ to $8.29 \%$, which indirectly illustrates that the $\mathrm{TiO}_{\mathrm{x}}$ nucleation progressed in this chemical bond. The reduction in chemical bonding states containing fluorine also indicates the transition of the triboelectric surface from PTFE to $\mathrm{TiO}_{\mathrm{x}}$. Therefore, the reduction in the triboelectric performance is related to changes in the triboelectric property of the PTFE surface. However, when the coverage of the $\mathrm{TiO}_{\mathrm{x}}$ layer at each ALD process is considered, the triboelectric performance of the $100-\mathrm{TiO}_{\mathrm{x}}$ sample should be greater than the other ALD processed samples. The largest signal loss in the $100-\mathrm{TiO}_{x}$ sample is based on the possible physical phenomenon during the ALD process. During the ALD process, the PTFE surface is exposed to two different atmospheres consisting of two different precursors, TTIP and $\mathrm{H}_{2} \mathrm{O}$, at a relatively high temperature $\left(150^{\circ} \mathrm{C}\right)$. When handling the polymers at a certain temperature, the glass transition temperature should be considered. At the glass transition temperature, the rigidity and viscosity of the polymer decrease, the fluidity of the solid increases and the molecular motion intensifies [53]. The glass transition temperature of PTFE is approximately $120^{\circ} \mathrm{C}[54]$, which means that during the ALD process, the PTFE polymer chain is relatively released. A relaxed PTFE chain makes more space for atoms or molecules, and it enables the precursor molecules to infiltrate the PTFE film. Therefore, while the PTFE layer thermally deforms, the precursor molecules can infuse into the PTFE layer [55]. Diffused precursor molecules can deflect the electrostatic induction caused by surface charges on the composite surface and can reduce the corresponding triboelectric performance. As the ALD cycle is increased, the amount of diffused precursors may increase. However, $\mathrm{TiO}_{x}$ nanoparticles are able to capture electrons in oxygen-deficient sites [56]. The oxygen-deficient sites are electrically positive; therefore, they can act as electron trapping sites. Figure $3 \mathrm{f}$ shows the proposed mechanism for enhancing the triboelectric performance of $\mathrm{ALD}^{-\mathrm{TiO}_{\mathrm{x}}}$ /PTFE TENGs. As both PTFE and $\mathrm{TiO}_{\mathrm{x}}$ particles co-exist with relatively low ALD cycles (from 100 to 500 cycles), contact electrification with the $\mathrm{Al}$ sheet occurs in both PTFE and ALD-TiO ${ }_{x}$ particles. When the $\mathrm{Al}$ sheet is in contact with the $\mathrm{TiO}_{\mathrm{x}}$ particles, surface charges are formed on $\mathrm{TiO}_{\mathrm{x}}$ particles. Additionally, the free electrons in the $\mathrm{Al}$ sheet can be trapped in oxygen-deficient sites in $\mathrm{TiO}_{\mathrm{x}}$. The trapped electrons can compensate for the initial surface charge loss induced by changes in the contact material from PTFE to $\mathrm{TiO}_{\mathrm{x}}$. By increasing the subsequent ALD process cycles, which lead to the uniform distribution of $\mathrm{TiO}_{x}$ particles, the possibility of electron trapping could be improved. Therefore, the signal loss from changes in tribo-material and electrostatic induction could be compensated.

\subsection{Moisture Passivation of $\mathrm{TiO}_{x}$ and Triboelectric Behaviors}

After confirming the base triboelectric behaviors of the ALD-TiO $/$ PTFE films, the humidity stabilities were evaluated. For this evaluation, all samples were contained in an environment-controlled chamber ( $\mathrm{RH} \mathrm{99 \%} \mathrm{and} \mathrm{room} \mathrm{temperature)} \mathrm{for} 24 \mathrm{~h}$. The triboelectric performances were measured immediately upon removal from the chamber. Furthermore, the triboelectric performances of the $\mathrm{ALD}-\mathrm{TiO}_{\mathrm{x}} / \mathrm{PTFE}$ films were evaluated to confirm their reusability after the natural drying process at room temperature, as shown in Figure 4 and Figure S5. Figure 4(ai-aiii) show the measured open circuit voltage $\left(\mathrm{V}_{\mathrm{OC}}\right)$, short circuit current $\left(\mathrm{I}_{\mathrm{SC}}\right)$, and charge density $(\sigma)$, respectively. The light green bars indicate the triboelectric behaviors of the as-deposited $\mathrm{ALD}-\mathrm{TiO}_{\mathrm{x}} / \mathrm{PTFE}$ films. The light blue bars represent the average triboelectric performances after the humidity exposure. Yellow bars show the average triboelectric performance after the natural drying process. After humidity exposure, the pristine PTFE film produced a voltage of $20.3 \mathrm{~V}$ and a current of $0.69 \mu \mathrm{A}$, and the accumulated charges were $3.26 \mathrm{nC} / \mathrm{cm}^{2}$. The output loss rate was 
calculated and is displayed in Figure 4(bi-biii). The black dots indicate the output loss rate after humidity exposure and red dots show the signal loss rate after the natural drying process. Compared with the triboelectric performances at the dry condition (As-dep), the overall output decreased approximately $30 \%$. Interestingly, the $100-\mathrm{TiO}_{x} / \mathrm{PTFE}$ film showed better passivation capability than the pristine PTFE film. The 100-TiO $x /$ PTFE film generated a voltage of $5.4 \mathrm{~V}$ and current of $0.19 \mu \mathrm{A}$, with accumulated charges of $0.73 \mathrm{nC} / \mathrm{cm}^{2}$. Reduction rates of the voltage, current, and charge density were $11 \%, 17.4 \%$, and $9.7 \%$, respectively. The reduction rates were lower than in the pristine PTFE film. The $300-\mathrm{TiO}_{\mathrm{x}} / \mathrm{PTFE}$ film produced a voltage of $10 \mathrm{~V}$ and a current of $0.26 \mu \mathrm{A}$, respectively. The accumulated charges were $1.5 \mathrm{nC} / \mathrm{cm}^{2}$. The voltage was reduced approximately $12.7 \%$, the current was reduced approximately $21 \%$, and the charge density decreased approximately $13 \%$ compared with the triboelectric outputs of $300-\mathrm{TiO}_{x} /$ PTFE film in the dry condition. However, the $500-\mathrm{TiO}_{\mathrm{x}} / \mathrm{PTFE}$ film shows a relatively poor moisture passivation ability compared with the 100 and $300-\mathrm{TiO}_{x} / \mathrm{PTFE}$ films. A $\sigma$ of $1.7 \mathrm{nC} / \mathrm{cm}^{2}$ was formed on the $500-\mathrm{TiO}_{\mathrm{x}} / \mathrm{PTFE}$ film, and the corresponding $\mathrm{V}_{\mathrm{OC}}$ and $\mathrm{I}_{\mathrm{SC}}$ were $11.1 \mathrm{~V}$ and $0.32 \mu \mathrm{A}$, respectively. The signal loss rates of $\mathrm{V}_{\mathrm{OC}}, \mathrm{I}_{\mathrm{SC}}$, and $\sigma$ were $32.9 \%, 41 \%$, and $38 \%$, respectively. The signal loss rates of the 500- $\mathrm{TiO}_{\mathrm{x}} /$ PTFE films were less than the pristine PTFE film, indicating that the ALD process longer than 500 cycles did not improve the moisture passivation. The $2000-\mathrm{TiO}_{\mathrm{x}} / \mathrm{PTFE}$ film shows the lowest moisture passivation capability among the ALD-TiO $/$ PTFE samples. After the humidity exposure, the 2000-TiO $/$ PTFE film produced a $\mathrm{V}_{\mathrm{OC}}$ of $2.5 \mathrm{~V}$, an $\mathrm{I}_{\mathrm{SC}}$ of $0.08 \mu \mathrm{A}$, and measured $\sigma$ of $0.4 \mathrm{nC} / \mathrm{cm}^{2}$. The $\mathrm{V}_{\mathrm{OC}}$ signal dropped by approximately $57 \%$, the ISC signal was reduced approximately $53 \%$, and $\sigma$ decreased by approximately $60 \%$. The moisture passivation mechanism can be explained based on the role of the oxygen-deficient site and hydrophobicity of ALD-TiO $/$ PTFE films. The oxygen-deficient site can absorb oxygen ions [56]. Figure 5a shows the Ti $2 p$ spectrum of the $300-\mathrm{TiO}_{\mathrm{x}} / \mathrm{PTFE}$ film after humidity exposure. Compared with the Ti $2 p$ spectrum in Figure 2c, the portion of oxygen-deficient sites $\left(\mathrm{Ti}^{3+}\right)$ decreased from $39.14 \%$ to $4.78 \%$. As shown in Figure $\mathrm{S} 2 \mathrm{~b}$, the $\mathrm{O} 1 \mathrm{~s}$ spectrum of the $300-\mathrm{TiO}_{\mathrm{x}} / \mathrm{PTFE}$ film also designates the decrease in oxygen-deficient sites. The $\mathrm{TiO}_{x}$ layer can absorb the $\mathrm{H}_{2} \mathrm{O}$ from air and can protect the PTFE surface from moisture in the environment, as shown in Figure 5b. As shown in Figure S3a, in the 500- $\mathrm{TiO}_{x} / \mathrm{PTFE}$ film, there was $43.3 \% \mathrm{Ti}^{3+}$ and a decrease to $11 \%$ after humidity exposure. Therefore, this passivation mechanism is also valid for explaining the triboelectric behavior of 500- $\mathrm{TiO}_{\mathrm{x}} / \mathrm{PTFE}$ film. In addition to the absorption of $\mathrm{H}_{2} \mathrm{O}$, the oxygen-deficient site can trap the electrons. However, after the oxygen-deficient site absorbs $\mathrm{H}_{2} \mathrm{O}$ from the air, the possibility of electron trapping can decrease. Therefore, it is difficult to obtain charge compensation by electron trapping. Therefore, 500-TiO $/$ PTFE, which has a large amount of $\mathrm{Ti}^{3+}$, can have a relatively larger signal loss than the 100 and $300-\mathrm{TiO}_{\mathrm{x}} / \mathrm{PTFE}$ films. The $\mathrm{TiO}_{2}$ film is grown after 2000 ALD cycles, as shown in Figures S1e and S3b. Therefore, $\mathrm{H}_{2} \mathrm{O}$ trapping-based passivation is more difficult than particle $\mathrm{TiO}_{\mathrm{x}} /$ PTFE films. Furthermore, $\mathrm{TiO}_{2}$ is a common hydrophilic material. Thus, $\mathrm{H}_{2} \mathrm{O}$ molecules can easily bind the $\mathrm{TiO}_{x}$ layer and form a thin conductive layer, which can dissipate the surface charges and reduce the triboelectric performance.

After confirming the moisture passivation mechanism, we measured triboelectric performances after a natural drying process at room temperature for $24 \mathrm{~h}$. The triboelectric performance of PTFE was noticeably recovered after natural drying. The measured $\mathrm{V}_{O C}$, $\mathrm{I}_{\mathrm{SC}}$, and $\sigma$ were $28.6 \mathrm{~V}, 0.94 \mu \mathrm{A}$, and $4.46 \mathrm{nC} / \mathrm{cm}^{2}$, respectively. The recovered triboelectric signals and charge density were the same as approximately $96 \%$ of outputs at the dry condition. However, the ALD-TiO $/$ PTFE films show a relatively low recovery rate compared with the pristine PTFE film. Triboelectric performances of 100- $\mathrm{TiO}_{\mathrm{x}} / \mathrm{PTFE}$ recovered by approximately 5 to $8 \%$ (91-96\% of outputs at the dry condition) and the corresponding $\mathrm{V}_{\mathrm{OC}}$ and $\mathrm{I}_{\mathrm{SC}}$ were $5.2 \mathrm{~V}$ and $0.22 \mu \mathrm{A}$. The surface charge density was $0.78 \mathrm{nC} / \mathrm{cm}^{2}$. The $300-\mathrm{TiO}_{x} /$ PTFE showed a similar recovery rate, 6 to $9 \%$ (87-94\% of performance at the dry condition), as much as that of the $100-\mathrm{TiO}_{x} /$ PTFE. The accumulated charge was $1.6 \mathrm{nC} / \mathrm{cm}^{2}$ and the detected open circuit voltage and short circuit current were $10.2 \mathrm{~V}$ and $0.28 \mu \mathrm{A}$, 
respectively. The $500-\mathrm{TiO}_{\mathrm{x}} / \mathrm{PTFE}$ film produced a $\mathrm{V}_{\mathrm{OC}}$ of $12.7 \mathrm{~V}$ and $\mathrm{I}_{\mathrm{SC}}$ of $0.44 \mu \mathrm{A}$, which were 9 and $22 \%$ recovered signals $(68-80 \%$ of the performance in the dry condition), respectively. The charge density was $1.9 \mathrm{nC} / \mathrm{cm}^{2}$, which was recovered to approximately $7 \%$. The output signals of the $2000-\mathrm{TiO}_{\mathrm{x}} / \mathrm{PTFE}$ film was barely recovered to approximately $0.1 \%$ to $6 \%(42-49 \%$ of the performance at the dry condition). The detected surface charge was $0.47 \mathrm{nC} / \mathrm{cm}^{2}$ and the corresponding $\mathrm{V}_{\mathrm{OC}}$ and $\mathrm{I}_{\mathrm{SC}}$ were $2.46 \mathrm{~V}$ and $0.08 \mu \mathrm{A}$, respectively. The output recovery rates indicate the hysteresis of the triboelectric performance. The hysteresis of triboelectric outputs is related to the $\mathrm{TiO}_{x}$ transformation to $\mathrm{TiO}_{2}$ as well as the presence of a thin $\mathrm{H}_{2} \mathrm{O}$ layer. To completely recover the triboelectric performance after the natural drying process, the absorbed oxygen has to break and an ALD-deposited layer needs to transform to the $\mathrm{TiO}_{\mathrm{x}}$ layer. However, $\mathrm{TiO}_{2}$ is a stable chemical state, and it is difficult to break with energy at room temperature. Thus, original oxygen-deficient sites can still be occupied with $\mathrm{H}_{2} \mathrm{O}$ absorbed during humidity exposure process. A decrease in oxygen-deficient sites leads to the low recovery rate of $\mathrm{ALD}-\mathrm{TiO}_{\mathrm{x}} / \mathrm{PTFE}$ films. In addition, because of the increased hydrophilicity of the $\mathrm{TiO}_{x}$ layer, it is possible that the $\mathrm{H}_{2} \mathrm{O}$ layer could remain on the $\mathrm{TiO}_{x}$ layer. Thus, the remaining $\mathrm{H}_{2} \mathrm{O}$ layer can dissipate the surface charges. Therefore, the corresponding triboelectric outputs of the 2000-TiO $/$ /PTFE film could be limited after the natural drying process. Our moisture passivation technique can decrease the peak triboelectric signal because of the transition of the tribo-material and diffusion of precursors during the ALD process. However, the technique can improve the moisture stability of PTFE by approximately three times. Thus, we expect that our moisture passivation technique can be utilized to preserve the accuracy of triboelectric sensors in a highly humid environment.

(a) i)

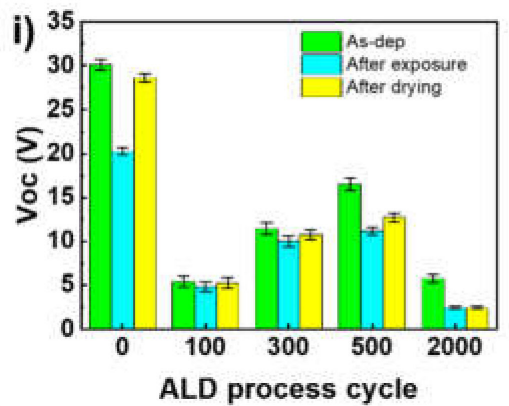

(b) i)

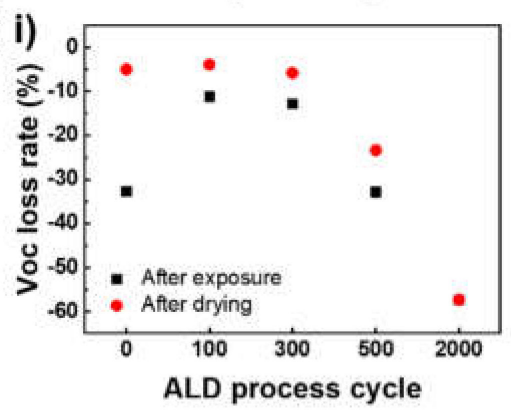

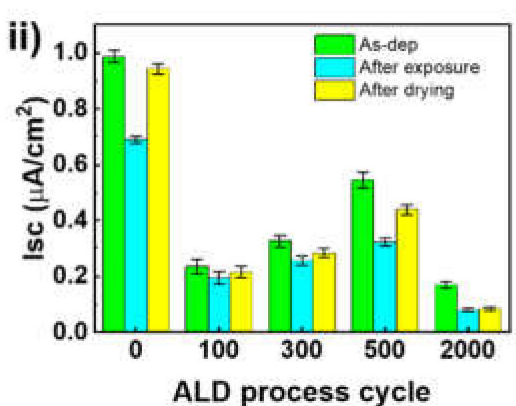

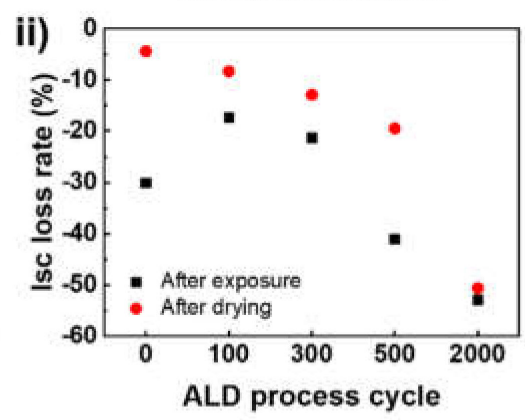

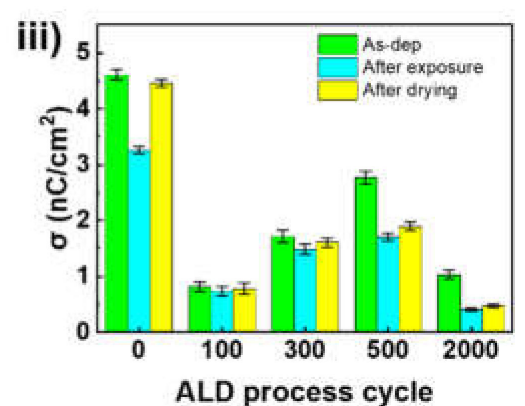

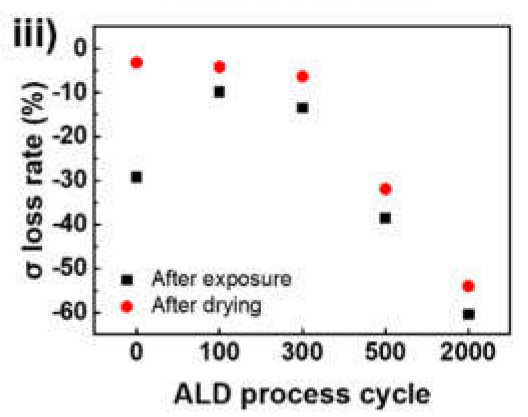

Figure 4. Effect of moisture on the triboelectric outputs of $\mathrm{ALD}-\mathrm{TiO}_{\mathrm{x}} / \mathrm{PTFE}$ films. (a) Comparison of triboelectric signals after moisture exposure and natural drying process. (b) Triboelectric signal loss rate of ALD-TiO ${ }_{x} /$ PTFE films after moisture exposure and drying process as a function of ALD cycles; (i) open circuit voltage ( $\left.\mathrm{V}_{\mathrm{OC}}\right)$, (ii) short circuit current ( $\mathrm{I}_{\mathrm{SC}}$ ), and (iii) charge density $(\sigma)$. 


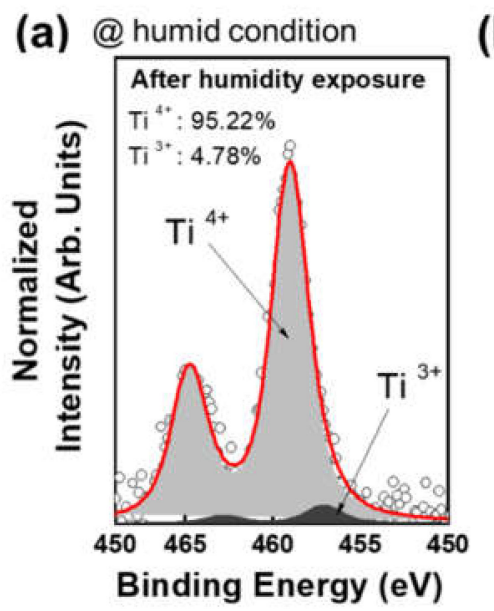

(b)

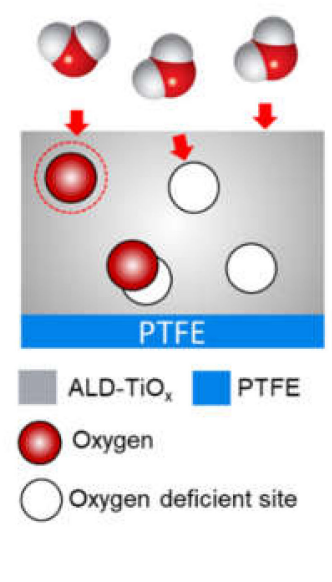

Figure 5. Change in the chemical bonding state after humidity exposure and relevant mechanism. (a) Deconvoluted Ti $2 p$ spectrum after moisture exposure with $\mathrm{RH} 99 \%$ at room temperature. (b) Schematic illustration of humidity passivation mechanism according to the oxygen deficient sites.

\section{Conclusions}

In this work, we proposed a novel moisture passivation technique using a $\mathrm{TiO}_{\mathrm{x}}$ layer deposited by the ALD for triboelectric mechanical sensors. The $\mathrm{TiO}_{\mathrm{x}}$ layer on a PTFE film was investigated by 100, 300, 500, and 2000 ALD process cycles. At a few ALD process cycles from 100 to $500, \mathrm{TiO}_{\mathrm{x}}$ layers were grown as islands because of the ALD nucleation mechanism on the polymer surfaces. At the most ALD cycles (2000 ALD process cycles), the $\mathrm{ALD}-\mathrm{TiO}_{\mathrm{x}}$ layer was grown as a uniform film on a PTFE film. Due to the transformation of tribo-materials from $\mathrm{PTFE}$ to $\mathrm{TiO}_{\mathrm{x}} / \mathrm{PTFE}$, the base triboelectric signals were reduced over $50 \%$. However, oxygen-deficient sites in the $\mathrm{TiO}_{\mathrm{x}}$ layer compensate the tribo-material transition caused surface charge loss by trapping electrons in the $\mathrm{Al}$ electrode. ALD-TiO grown with few ALD cycles shows better moisture stability and triboelectric signal at humid conditions, which are the same as $90 \%$ of outputs at the dry condition, while pristine PTFE generated $70 \%$ of outputs at the dry condition. The improved moisture stability is based on the $\mathrm{H}_{2} \mathrm{O}$ absorption by an oxygen-deficient site in the $\mathrm{TiO}_{\mathrm{x}}$ layer. Due to the improved moisture stability, the triboelectric mechanical sensors can preserve the fine sensing resolution at the highly humid environment. We expected that our approach can be used to maintain the triboelectric signal of triboelectric mechanical sensors in harsh environments.

Supplementary Materials: The following are available online at https:/ /www.mdpi.com/article/10 .3390/nano11071795/s1, Figure S1: FE-SEM and EDS elemental mapping of Ti on ALD-TiOx/PTFE films, Figure S2: deconvoluted XPS O 1s spectra of 300 ALD-TiOx/PTFE film, Figure S3: deconvoluted XPS Ti 2p spectra of 500 and 2000 ALD-TiOx/PTFE films, Figure S4: mechanical durability test, Figure S5: measured triboelectric signals at the dry condition, at highly humid condition, and after the natural drying process.

Author Contributions: Conceptualization, D.C., H.-B.-R.L. and W.K.; data curation, W.K., S.Y.; formal analysis, W.K.; funding acquisition, D.C., W.K.; investigation and methodology, W.K., S.Y. and C.T.N.; project administration and supervision, D.C. and H.-B.-R.L.; writing-original draft, W.K., S.Y.; writing-review and editing, H.-B.-R.L. and D.C.; W.K. and S.Y. equally contributed to this work. All authors have read and agreed to the published version of the manuscript.

Funding: This research was financially supported by the Mid-Career Research Program (NRF2019R1A2C2083934), Post-Doctoral Domestic Training Program (NRF-2020R1A6A3A01096572) through the National Research Foundation of Korea (NRF) grant funded by the Ministry of Science and ICT and the Ministry of Education.

Conflicts of Interest: The authors declare no conflict of interest. 


\section{References}

1. Verpoorten, E.; Massaglia, G.; Ciardelli, G.; Pirri, C.F.; Quaglio, M. Design and optimization of piezoresistive PEO/PEDOT:PSS electrospun nanofibers for wearable flex sensors. Nanomaterials 2020, 10, 2166. [CrossRef]

2. Herren, B.; Charara, M.; Saha, M.C.; Altan, M.C.; Liu, Y. Rapid microwave polymerization of porous nanocomposites with piezoresistive sensing function. Nanomaterials 2020, 10, 233. [CrossRef]

3. Luo, N.; Dai, W.; Li, C.; Zhou, Z.; Lu, L.; Poon, C.C.Y.; Chen, S.-C.; Zhang, Y.; Zhao, N. Flexible piezoresistive sensor patch enabling ultralow power cuffless blood pressure measurement. Adv. Funct. Mater. 2016, 26, 1178-1187. [CrossRef]

4. Boudaden, J.; Klumpp, A.; Endres, H.-E.; Eisele, I. Towards low cost and low temperature capacitive $\mathrm{CO}_{2}$ sensors based on amine functionalized silica nanoparticles. Nanomaterials 2019, 9, 1097. [CrossRef]

5. Shen, X.-Q.; Li, M.-D.; Ma, J.-P.; Shen, Q.-D. Skin-inspired pressure sensor with MXene/P(VDF-TrFE-CFE) as active layer for wearable electronics. Nanomaterials 2021, 11, 716. [CrossRef]

6. Yang, H.J.; Lee, J.Y.; Yu, W.-R. Carbon nanotube fiber assemblies with braided insulation layers for washable capacitive textile touch sensors. Funct. Compos. Struct. 2020, 2, 015007. [CrossRef]

7. Wang, A.; Hu, M.; Zhou, L.; Qiang, X. Self-powered wearable pressure sensors with enhanced piezoelectric properties of aligned $\mathrm{P}(\mathrm{VDF}-\mathrm{TrFE})$ /MWCNT composites for monitoring human physiological and muscle motion signs. Nanomaterials 2018, 8, 1021. [CrossRef] [PubMed]

8. Tian, G.; Deng, W.; Gao, Y.; Xiong, D.; Yan, C.; He, X.; Yang, T.; Jin, L.; Chu, X.; Zhang, H.; et al. Rich lamellar crystal baklava-structured PZT/PVDF piezoelectric sensor toward individual table tennis training. Nano Energy 2019, 59, 574-581. [CrossRef]

9. Han, D.-H.; Kang, L.-H. Piezoelectric properties of paint sensor according to piezoelectric materials. Funct. Compos. Struct. 2020, 2, 025002. [CrossRef]

10. Wang, J.; Qian, S.; Yu, J.; Zhang, Q.; Yuan, Z.; Sang, S.; Zhou, X.; Sun, L. Flexible and wearable PDMS-based triboelectric nanogenerator for self-powered tactile sensing. Nanomaterials 2019, 9, 1304. [CrossRef] [PubMed]

11. Chen, T.; Shi, Q.; Yang, Z.; Liu, J.; Liu, H.; Sun, L.; Lee, C. A self-powered six-axis tactile sensor by using triboelectric mechanism. Nanomaterials 2018, 8, 503. [CrossRef] [PubMed]

12. Zou, J.; Zhang, M.; Huang, J.; Bian, J.; Jie, Y.; Willander, M.; Cao, X.; Wang, N.; Wang, Z.L. Coupled supercapacitor and triboelectric nanogenerator boost biomimetic pressure sensor. Adv. Energy Mater. 2018, 8, 1702671. [CrossRef]

13. Fan, F.-R.; Lin, L.; Zhu, G.; Wu, W.; Zhang, R.; Wang, Z.L. Transparent triboelectric nanogenerators and self-powered pressure sensors based on micropatterned plastic films. Nano Lett. 2012, 12, 3109-3114. [CrossRef]

14. Dhakar, L.; Gudla, S.; Shan, X.; Wang, Z.; Tay, F.E.H.; Heng, C.-H.; Lee, C. Large scale triboelectric nanogenerator and self-powered pressure sensor array using low cost roll-to-roll UV embossing. Sci. Rep. 2016, 6, 22253. [CrossRef] [PubMed]

15. Wang, S.; He, M.; Weng, B.; Gan, L.; Zhao, Y.; Li, N.; Xie, Y. Stretchable and wearable triboelectric nanogenerator based on kinesio tape for self-powered human motion sensing. Nanomaterials 2018, 8, 657. [CrossRef]

16. Dhakar, L.; Pitchappa, P.; Tay, F.E.H.; Lee, C. An intelligent skin based self-powered finger motion sensor integrated with triboelectric nanogenerator. Nano Energy 2016, 19, 532-540. [CrossRef]

17. Wu, Z.; Ding, W.; Dai, Y.; Dong, K.; Wu, C.; Zhang, L.; Lin, Z.; Cheng, J.; Wang, Z.L. Self-powered multifunctional motion sensor enabled by magnetic-regulated triboelectric nanogenerator. ACS Nano 2018, 12, 5726-5733. [CrossRef]

18. Ra, Y.; Choi, J.H.; La, M.; Park, S.J.; Choi, D. Development of a highly transparent and flexible touch sensor based on triboelectric effect. Funct. Compos. Struct. 2019, 1, 045001. [CrossRef]

19. Anaya, V.D.; He, T.; Lee, C.; Yuce, M.R. Self-powered eye motion sensor based on triboelectric interaction and near-field electrostatic induction for wearable assistive technologies. Nano Energy 2020, 72, 104675. [CrossRef]

20. Chen, T.; Shi, Q.; Li, K.; Yang, Z.; Liu, H.; Sun, L.; Dziuban, J.A.; Lee, C. Investigation of position sensing and energy harvesting of a flexible triboelectric touch pad. Nanomaterials 2018, 8, 613. [CrossRef]

21. Chen, J.; Zhu, G.; Yang, W.; Jing, Q.; Bai, P.; Yang, Y.; Hou, T.-C.; Wang, Z.L. Harmonic-resonator-based triboelectric nanogenerator as a sustainable power source and a self-powered active vibration sensor. Adv. Mater. 2013, 25, 6094-6099. [CrossRef] [PubMed]

22. He, Q.; Wu, Y.; Feng, Z.; Sun, C.; Fan, W.; Zhou, Z.; Meng, K.; Fan, E.; Yang, J. Triboelectric vibration sensor for a human-machine interface built on ubiquitous surfaces. Nano Energy 2019, 59, 689-696. [CrossRef]

23. Kim, W.; Bhatia, D.; Hwang, H.J.; Choi, K.; Choi, D. Double impact triboelectric nanogenerators for harvesting broadband vibrations from vehicles. Funct. Compos. Struct. 2019, 1, 035003. [CrossRef]

24. Jing, Q.; Zhu, G.; Wu, W.; Bai, P.; Xie, Y.; Han, R.P.S.; Wang, Z.L. Self-powered triboelectric velocity sensor for dual-mode sensing of rectified linear and rotary motions. Nano Energy 2014, 10, 305-312. [CrossRef]

25. Yi, F.; Lin, L.; Niu, S.; Yang, J.; Wu, W.; Wang, S.; Liao, Q.; Zhang, Y.; Wang, Z.L. Self-powered trajectory, velocity, and acceleration tracking of a moving object/body using a triboelectric sensor. Adv. Funct. Mater. 2014, 24, 7488-7494. [CrossRef]

26. Heo, D.; Chung, J.; Kim, B.; Yong, H.; Shin, G.; Cho, J.-W.; Kim, D.; Lee, S. Triboelectric speed bump as a self-powered automobile warning and velocity sensor. Nano Energy 2020, 72, 104719. [CrossRef]

27. Wang, H.; Xiang, Z.; Giorgia, P.; Mu, X.; Yang, Y.; Wang, Z.L.; Lee, C. Triboelectric liquid volume sensor for self-powered lab-on-chip applications. Nano Energy 2016, 23, 80-88. [CrossRef]

28. Chen, J.; Guo, H.; Zheng, J.; Huang, Y.; Liu, G.; Hu, C.; Wang, Z.L. Self-powered triboelectric micro liquid/gas flow sensor for microfluidics. ACS Nano 2016, 10, 8104-8112. [CrossRef] 
29. Lin, Z.-H.; Zhu, G.; Zhou, Y.S.; Yang, Y.; Bai, P.; Chen, J.; Wang, Z.L. A self-powered triboelectric nanosensor for mercury ion detection. Angew. Chem. Int. Ed. 2013, 52, 5065-5069. [CrossRef]

30. Shin, S.-H.; Kwon, Y.H.; Kim, Y.-H.; Jung, J.-Y.; Nah, J. Triboelectric hydrogen gas sensor with Pd functionalized surface. Nanomaterials 2016, 6, 186. [CrossRef]

31. Wen, Z.; Chen, J.; Yeh, M.-H.; Guo, H.; Li, Z.; Fan, X.; Zhang, T.; Zhu, L.; Wang, Z.L. Blow-driven triboelectric nanogenerator as an active alcohol breath analyzer. Nano Energy 2015, 16, 38-46. [CrossRef]

32. Chen, C.; Wen, Z.; Wei, A.; Xie, X.; Zhai, N.; Wei, X.; Peng, M.; Liu, Y.; Sun, X.; Yeow, J.T.W. Self-powered on-line ion concentration monitor in water transportation driven by triboelectric nanogenerator. Nano Energy 2019, 62, 442-448. [CrossRef]

33. Wu, C.; Wang, A.C.; Ding, W.; Guo, H.; Wang, Z.L. Triboelectric nanogenerator: A foundation of the energy for the new era. Adv. Energy Mater. 2019, 9, 1802906. [CrossRef]

34. Zhu, G.; Peng, B.; Chen, J.; Jing, Q.; Lin Wang, Z. Triboelectric nanogenerators as a new energy technology: From fundamentals, devices, to applications. Nano Energy 2015, 14, 126-138. [CrossRef]

35. Zhou, L.; Liu, D.; Wang, J.; Wang, Z.L. Triboelectric nanogenerators: Fundamental physics and potential applications. Friction 2020, 8, 481-506. [CrossRef]

36. Nguyen, V.; Yang, R. Effect of humidity and pressure on the triboelectric nanogenerator. Nano Energy 2013, 2, 604-608. [CrossRef]

37. Kim, K.N.; Chun, J.; Kim, J.W.; Lee, K.Y.; Park, J.-U.; Kim, S.-W.; Wang, Z.L.; Baik, J.M. Highly stretchable 2D fabrics for wearable triboelectric nanogenerator under harsh environments. ACS Nano 2015, 9, 6394-6400. [CrossRef]

38. Chandrasekhar, A.; Vivekananthan, V.; Khandelwal, G.; Kim, S.J. A fully packed water-proof, humidity resistant triboelectric nanogenerator for transmitting Morse code. Nano Energy 2019, 60, 850-856. [CrossRef]

39. Jao, Y.-T.; Yang, P.-K.; Chiu, C.-M.; Lin, Y.-J.; Chen, S.-W.; Choi, D.; Lin, Z.-H. A textile-based triboelectric nanogenerator with humidity-resistant output characteristic and its applications in self-powered healthcare sensors. Nano Energy 2018, 50, 513-520. [CrossRef]

40. Shen, J.; Li, Z.; Yu, J.; Ding, B. Humidity-resisting triboelectric nanogenerator for high performance biomechanical energy harvesting. Nano Energy 2017, 40, 282-288. [CrossRef]

41. Graham, S.A.; Dudem, B.; Patnam, H.; Mule, A.R.; Yu, J.S. Integrated design of highly porous cellulose-loaded polymer-based triboelectric films toward flexible, humidity-resistant, and sustainable mechanical energy harvesters. ACS Energy Lett. 2020, 5, 2140-2148. [CrossRef]

42. Zhou, Q.; Lee, K.; Kim, K.N.; Park, J.G.; Pan, J.; Bae, J.; Baik, J.M.; Kim, T. High humidity- and contamination-resistant triboelectric nanogenerator with superhydrophobic interface. Nano Energy 2019, 57, 903-910. [CrossRef]

43. Lee, H.-B.-R.; Bent, S.F. A selective toolbox for nanofabrication. Chem. Mater. 2020, 32, 3323-3324. [CrossRef]

44. Lee, H.-B.-R. The era of atomic crafting. Chem. Mater. 2019, 31, 1471-1472. [CrossRef]

45. Chen, R.; Li, Y.-C.; Cai, J.-M.; Cao, K.; Lee, H.-B.-R. Atomic level deposition to extend Moore's law and beyond. Int. J. Extrem. Manuf. 2020, 2, 022002. [CrossRef]

46. Ding, S.-J.; Zhu, C.; Li, M.-F.; Zhang, D.W. Atomic-layer-deposited $\mathrm{Al}_{2} \mathrm{O}_{3}-\mathrm{HfO}_{2}-\mathrm{Al}_{2} \mathrm{O}_{3}$ dielectrics for metal-insulator-metal capacitor applications. Appl. Phys. Lett. 2005, 87, 053501. [CrossRef]

47. Zhu, C.; Cho, B.J.; Li, M.F. Atomic Layer Deposited High-k Films and Their Role in Metal-Insulator-Metal Capacitors for Si RF/Analog Integrated Circuit Applications. Chem. Vap. Depos. 2006, 12, 165-171. [CrossRef]

48. Ye, P.D.; Wilk, G.D.; Yang, B.; Kwo, J.; Chu, S.N.G.; Nakahara, S.; Gossmann, H.J.L.; Mannaerts, J.P.; Hong, M.; Ng, K.K.; et al. GaAs metal-oxide-semiconductor field-effect transistor with nanometer-thin dielectric grown by atomic layer deposition. Appl. Phys. Lett. 2003, 83, 180-182. [CrossRef]

49. Liu, H.; Ye, P.D. $\mathrm{MoS}_{2}$ dual-gate MOSFET with atomic-layer-deposited $\mathrm{Al}_{2} \mathrm{O}_{3}$ as top-gate dielectric. IEEE Electron. Device Lett. 2012, 33, 546-548. [CrossRef]

50. Cheng, Q.; Benipal, M.K.; Liu, Q.; Wang, X.; Crozier, P.A.; Chan, C.K.; Nemanich, R.J. $\mathrm{Al}_{2} \mathrm{O}_{3}$ and $\mathrm{SiO}_{2}$ atomic layer deposition layers on $\mathrm{ZnO}$ photoanodes and degradation mechanisms. ACS Appl. Mater. Interfaces 2017, 9, 16138-16147. [CrossRef]

51. Yang, X.; Liu, R.; Du, C.; Dai, P.; Zheng, Z.; Wang, D. Improving hematite-based photoelectrochemical water splitting with ultrathin $\mathrm{TiO}_{2}$ by atomic layer deposition. ACS Appl. Mater. Interfaces 2014, 6, 12005-12011. [CrossRef]

52. Kemell, M.; Färm, E.; Ritala, M.; Leskelä, M. Surface modification of thermoplastics by atomic layer deposition of $\mathrm{Al}_{2} \mathrm{O}_{3}$ and $\mathrm{TiO}_{2}$ thin films. Eur. Polym. J. 2008, 44, 3564-3570. [CrossRef]

53. Watari, K.; Iwao, T.; Yumoto, M. Structure change of PTFE by low-energy ion irradiation. Restraint of structure collapse by crosslinking structures. Electr. Eng. Jpn. 2012, 178, 1-7. [CrossRef]

54. Araki, Y. Thermal expansion coefficient of polytetrafluoroethylene in the vicinity of its glass transition at about $400{ }^{\circ} \mathrm{K}$. J. Appl. Polym. Sci. 1965, 9, 421-427. [CrossRef]

55. Parsons, G.N.; Atanasov, S.E.; Dandley, E.C.; Devine, C.K.; Gong, B.; Jur, J.S.; Lee, K.; Oldham, C.J.; Peng, Q.; Spagnola, J.C.; et al. Mechanisms and reactions during atomic layer deposition on polymers. Coord. Chem. Rev. 2013, 257, 3323-3331. [CrossRef]

56. Park, H.-W.; Huynh, N.D.; Kim, W.; Lee, C.; Nam, Y.; Lee, S.; Chung, K.-B.; Choi, D. Electron blocking layer-based interfacial design for highly-enhanced triboelectric nanogenerators. Nano Energy 2018, 50, 9-15. [CrossRef] 